\title{
A predator-prey model to explain cycles in credit-led economies
}

\author{
Óscar Dejuán* \\ Universidad de Castilla-La Mancha, Albacete, Spain \\ Daniel Dejuán-Bitriá \\ London School of Economics, UK
}

This paper develops a predator-prey model to explain cycles in credit-led economies. The predator is the part of the financial sector that issues credit money for non-output transactions. It increases the indebtedness ratio and inflates bubbles that eventually have a negative impact on the real rate of growth (the prey). From this basis, we build a couple of models that may lead to self-contained or explosive cycles. Even in the first case, there is a risk of a financial collapse when certain variables move far away from their longterm equilibrium positions. In order to tame the cycle and avoid extreme positions, governments should ban the expansion of credit money for the purchase of assets and introduce permanent checks to risky credit.

Keywords: business cycles, financial instability, predator-prey models, post-Keynesian economics

JEL codes: E12, E32, E44

\section{INTRODUCTION}

This is a theoretical paper whose backdrop is the credit boom leading to the financial crash of 2007 and the first great recession of the twenty-first century. This crisis witnesses the 'financial instability hypothesis' of Minsky (1964; 1982; 1986; 1992). It also shows that the 'originate-to-distribute model of banking,' which characterizes our financialized economy, has accelerated the deterioration of the debt structures. Section 2 revises the key data of this process in the USA - the epicenter of the financial turmoil.

The Minskyan 'financial instability hypothesis' is deployed by means of a predatorprey model. This model was introduced in the natural sciences by Lotka and Volterra. Through a system of differential equations, they captured the systemic interdependency among marine species. In Volterra (1926), the higher the population of whiting (prey), the higher the food ratio and population of sharks (predator). After a certain point, the smaller population of whiting is bound to check the expansion of sharks. The traditional idea of the survival of the fittest is not always true in nature, he concluded.

Goodwin (1967) introduced the predator-prey model to explain the counterclockwise movement in the employment rate and the labor share in income. A profit squeeze may damage the accumulation process and, therefore, the employment rate. Goodwin's model has prompted numerous extensions to the relation between

* Corresponding author: email: oscar.dejuan@uclm.es. 
distribution and accumulation. Goodwin et al. (1984) offer a survey. More recently, Arnim and Barrales (2015) have concluded that the Goodwin-Kalecki model of 'profit squeeze' continues to be the preferable approach to explain supply-driven cycles.

Taylor and O'Connell (1985) used a predator-prey model to formalize Minsky's hypothesis of an ongoing climate of financial fragility leading to economic crises. In a nutshell: the endogenous deterioration of the debt structure increases liquidity preference and checks productive investment.

Taylor and O'Connell (1985) was the seminal paper that encouraged post-Keynesian economists to study the dynamic competition between the real and financial sectors of the economy. ${ }^{1}$ The new models differ mostly on the variables playing the roles of prey and predator. For Asada $(2001 ; 2011)$, private debt is the predator, and income (related to capacity utilization) is the prey. In Dejuán and González-Calvet (2005), the predator is the rate of interest, while the prey is the rate of growth of real GDP. Fazzari et al. (2008) and Oreiro et al. (2013) relate the cashflow of firms (inversely related to the rate of interest) to their investment decisions. Taylor (2012) relates Minsky with Goodwin-style cycles.

Without using a proper predatory-prey model, Ryoo and Skott build a variety of stock-flow consistent models to show the relationship between the increasing leverage of firms, the capital gains resulting from the sale of stocks, and the investment decisions that depend on Tobin's $q$. The final effects on the real economy will depend on whether we adopt a Kaleckian view (capacity utilization closure) or a Kaldorian one (profit share closure). In the Kaldorian version, the real sector itself has an inherent tendency towards cyclical behavior ('short cycles'), along with the cyclical forces generated by endogenous changes in financial practices ('long waves') (Skott 1994; Ryoo and Skott 2008; Skott and Ryoo 2008; Ryoo 2013a; 2013b). ${ }^{2}$ Palley $(1994 ; 2011)$ contrasts the long financial cycles leading to financial crashes with the traditional business cycles. Palley (2013, p. 65) states that credit-led capitalism has developed a 'predator-prey' mechanism.

Our paper has also been influenced by Badhuri et al. (2006) and Werner (1997; $2005 ; 2015$ ). Badhuri et al. confront the real economy (from which output and profits accrue) and the virtual one that inflates bubbles and capital gains. Werner differentiates between the circuit of output transactions and the circuit of non-output transactions (assets). The first circuit is a positive-game. The second circuit is a zero-sum game where bubbles are inflated. He reinstates the 'quantity theory of credit' to explain asset inflation.

In our paper, the prey will be the productive sector represented by the rate of growth of real GDP. ${ }^{3}$ Since our interest is in the impact of financial forces, we will consider an economy that is growing at the autonomous trend marked by the expansion permanent autonomous demand, with inflation controlled by the central bank. In Section 3 we combine the Keynesian-Kaleckian principle of effective demand (Keynes 1936; Kalecki 1971) and the multiplier-accelerator mechanism. This is the supermultiplier model introduced by Hicks (1950), Serrano (1995), Bortis (1997), Dejuán (2005; 2016), and Serrano and Freitas (2015).

Following Werner (1997), the predator has been identified with the financial sector when it provides credit for non-output transactions. It brings about higher indebtedness

1. Semmler (1995) surveys the most important contributions. See also Asada et al. (2010).

2. Dafermos combines the insights of Godley, Lavoie, and Minsky in order to show the fragile link between income and credit-debt. See Godley and Lavoie (2006) and Dafermos (2014).

3. Traditional finance provides credit for output transactions. It is an important element in the process of income generation, distribution, and expenditure. 
ratios and bubbles that (eventually) damage the real economy. Section 4 analyses the forces that affect creditworthiness and their influences on aggregate demand: default rate, indebtedness ratio, burden of debt, vertigo-stampede effects, wealth effects.

In Section 5 (and in the mathematical Appendix 1) we build a variety of predatorprey models leading to self-contained or explosive cycles. Even the first ones may lead to a credit crunch and a recession. This happens when the gap between the current trend of certain variables and their long-term equilibrium rate becomes too broad. Arguably, one of the main contributions of this paper is the presence of gravity centers compatible with the principle of effective demand. The expected growth of permanent demand, provided it endures long enough, is an attractor of the growth of output at full capacity (not full employment). The same rate plus the inflation target fixed by the Central Bank marks the long-term equilibrium growth of credit. In a Sraffian mood, the fundamental value of assets (discounted at the normal rate of profit) becomes a gravity center of asset inflation (Sraffa 1960).

The conclusions of the paper are summed up in Section 6. In order to tame the cycle and avoid extreme positions, governments should ban the expansion of credit money for the purchase of assets and introduce permanent checks to risky credit.

\section{A GLANCE AT THE DYNAMICS OF THE KEY VARIABLES IN A CREDIT-LED ECONOMY}

The cyclical character of credit and its ability to influence the dynamics of the real economy was acknowledged a long time ago by Minsky $(1964 ; 1982 ; 1986)$ and Kindleberger (1978). What is new in our financialized economy is the rhythm enforced by the so called 'originate-to-distribute model of banking,' based on the connivance between traditional and shadow banks. The traditional banking system creates money simply by the granting of loans, mortgages included. The shadow banking system paves the way for credit expansion by securitizing these loans and disguising their risks. ${ }^{4}$

Figure 1 illustrates these points in the US economy, the epicenter of the financial turmoil. From 1994 to 2007 the share of credit for output transactions rose from 130 percent of GDP to 210 percent. Credit grew 5 percentage points faster than nominal GDP, which was expanding at historically high rates. The expansion of credit-backed securities was even more impressive: from 1.1 percent of GDP in 1990 to 13.5 percent in 2007, a 12-fold increase. It was the catalyst of credit expansion.

Credit implies debt. Such an identity allows us to interpret Figure 1 as the acceleration of the indebtedness ratio and the burden of debt. This burden may be imperceptible in the boom, most of all, if the shadow banking system manages to disguise it. In Figure 2 we observe that the default rate was kept constant in the 1990s, despite the strong growth rates of credit and output. It fell in the boom period that followed the short recession in 2000-2001, a fall that banks interpreted as an invitation to relax creditworthiness criteria. The default rate rose steeply four years later, announcing an imminent financial crash.

The expansion of credit since the mid 1990s pushed the American economy towards its potential (full capacity) output. A 4 percent growth of real GDP is certainly a high rate for any advanced economy. In principle, this could have unleashed strong

4. The financialization of the economy has been studied by Ryoo and Skott (2008), Skott and Ryoo (2008), Hein (2012), and Palley (2013). 
162 Review of Keynesian Economics, Vol. 6 No. 2

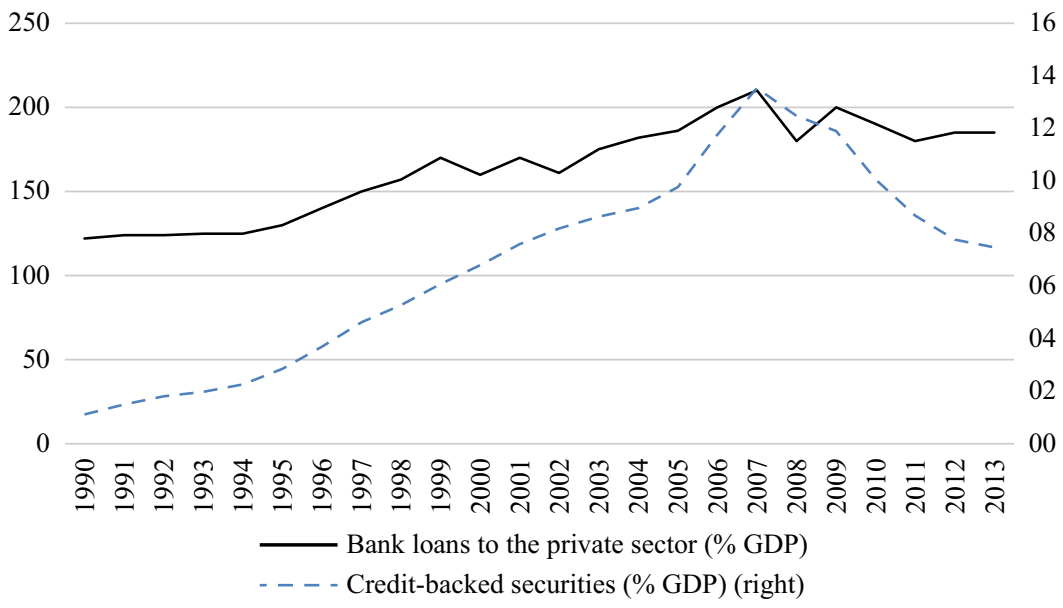

Source: FRED (Federal Reserve Bank of St Louis Economic Data).

Figure 1 Credit explosion through securitization and indebtedness ratio, USA

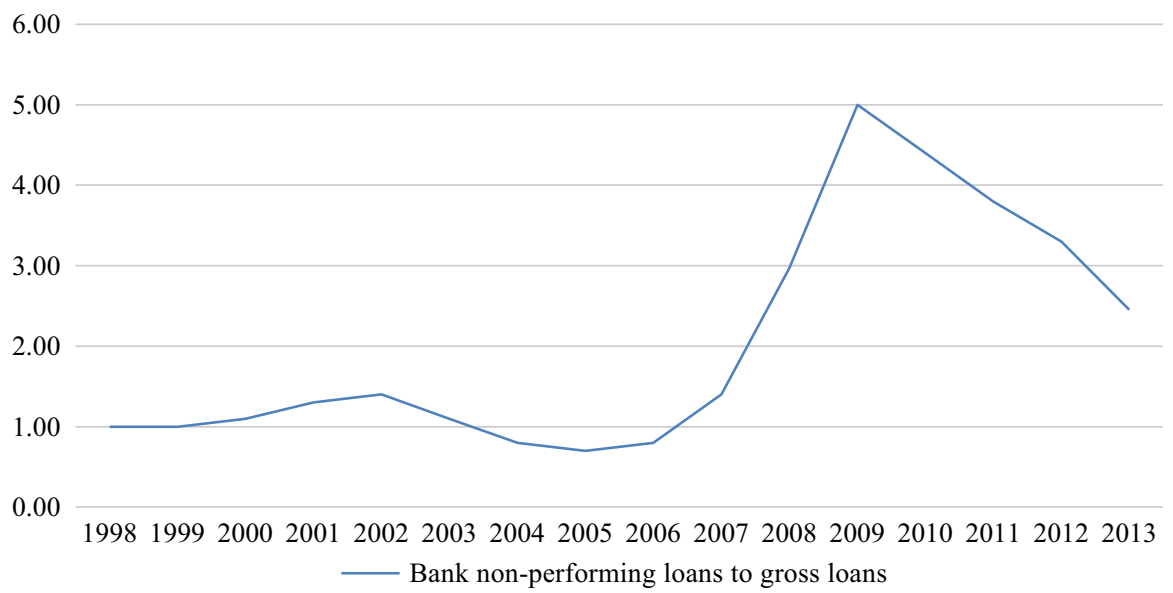

Source: FRED (Federal Reserve Bank of St Louis Economic Data).

Figure 2 Risky credit and default rates

inflationary pressures. Yet, as we see in Figure 3, inflation stayed at the low rates targeted by the Federal Reserve.

Figure 4 shows that credit expansion above the growth of nominal GDP raised asset prices. The acceleration of credit for non-output transactions in the mid 1990s led to a bubble in the stock exchange market that burst in 2000-2001. The next (and stronger) acceleration of credit after 2002 was able to inflate twin bubbles in the stock exchange and in the residential market. Both of them burst in 2007, triggering the worst financial crisis since 1929. 


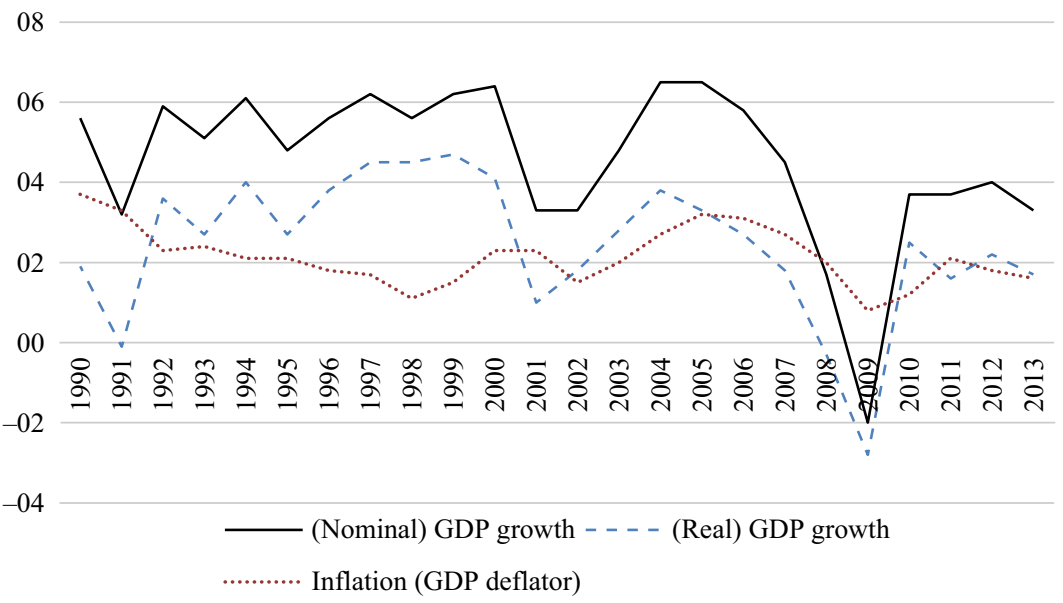

Source: FRED (Federal Reserve Bank of St Louis Economic Data).

Figure 3 Strong economic growth with low inflation

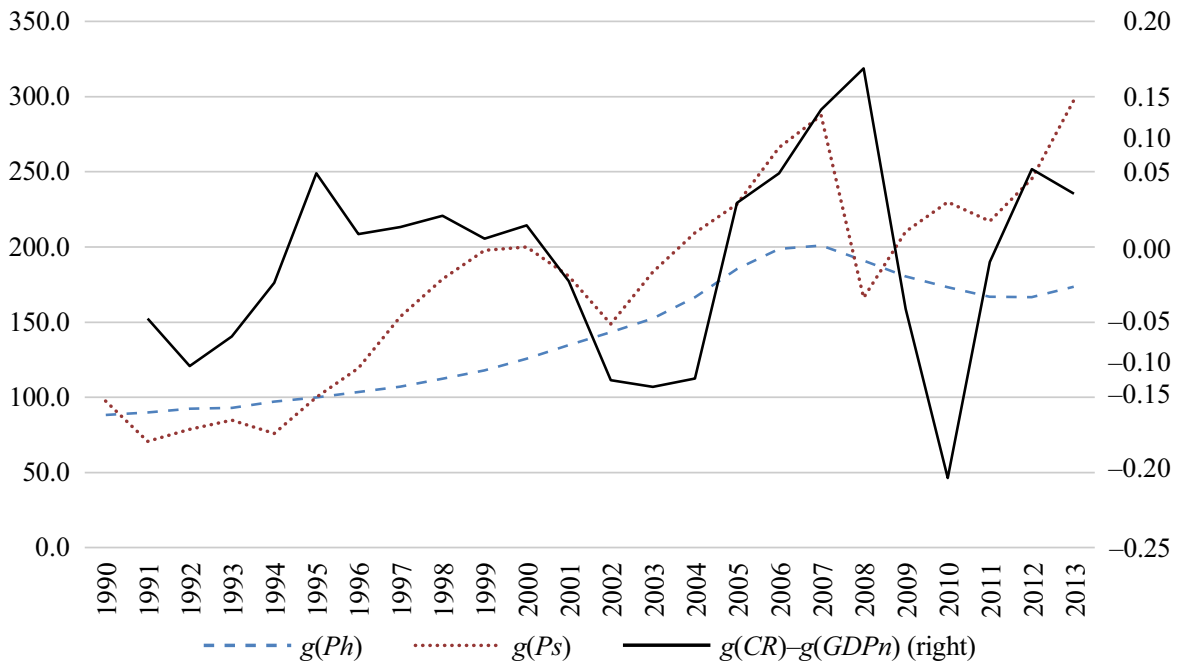

Note: $g(P h)=$ rate of growth of the house price index; $g(P s)=$ rate of growth of the price of shares in the stock exchange; $g(C R)=$ rate of growth of total credit; $g(G D P n)=$ rate of growth of nominal output. Sources: Own computations with data from FRED and NIPA.

Figure 4 Acceleration of credit for non-output transaction and asset bubbles, USA

The aforementioned figures are part of the stylized facts that our model is supposed to explain by means of a predator-prey model: the indebtedness ratio, the default rate, asset inflation ... The acceleration of credit for non-output transactions helps an economic boom for a time, but it sows the seeds of financial crashes leading to economic recessions - the kernel of Minsky's financial instability hypothesis. 


\section{THE PRODUCTIVE SECTOR: GROWTH OF OUTPUT}

To simplify our presentation we will consider a private, closed economy. In the productive sector (circuit for output transactions), firms produce final output $(Y)$. According to the Keynesian-Kaleckian principle of effective demand, $Y$ adjusts to expected demand $(D)$ at the normal prices that we identify with the Sraffian prices of production (Keynes 1936; Sraffa 1960; Kalecki 1971).

The following equations represent the equilibrium of output $\left(Y_{t}\right)$ in a given period $(t)$.

$$
\begin{gathered}
Y_{t}=D_{t}=C_{t}+I_{t}+Z_{t} \\
C_{t}=c \cdot Y_{d t}=c\left(1-t^{\prime}\right) \cdot Y_{t}=c\left(1-i^{\prime} \cdot \beta_{t}\right) \cdot Y_{t} \\
I_{t}=k^{*} \cdot g_{d}^{*} \cdot Y_{t} \\
Z_{t}=Z_{t}^{*}+Z_{t}^{\prime}
\end{gathered}
$$

$C$ stands for the induced consumption of households. It is a proportion $(c)$ of disposable income $\left(Y_{d}\right)$. We can also compute it by subtracting from $c$ the burden of debt that is treated as a transfer from debtors to the banking system: $t^{\prime}=i^{\prime} \cdot \beta_{t}$. Here $i^{\prime}$ is the gross interest rate that includes amortization allowances; $\beta_{t}=D B_{t} / Y_{t}$ is the indebtedness ratio or share of debt $(D B)$ in income. Note that induced consumption (and the multiplier that we will derive from it) depends on financial conditions.

I stands for business's induced investment of the expansionary type. According to the acceleration principle, firms expand capacity to match, in an efficient way, the expected increases in permanent demand. $k^{*}$ is the optimal or desired capital-output ratio. It corresponds to the normal rate of capacity utilization that we normalize at one $\left(u^{*}=1\right)$. The actual rate $\left(u_{t}\right)$ allows the adjustment of output to transient bursts of demand. $g_{d} *$ is the expected growth of permanent demand, the key variable in the Keynesian system (Eatwell 1983; 2012). Keynes emphasized the psychological elements encapsulated in the 'animal spirits' of entrepreneurs. In a growth model, we should also take into consideration objective forces. In our opinion, the most important one is the expected growth of permanent autonomous demand $\left(g_{z}{ }^{*}\right)$.

$Z$ stands for (proper) autonomous demand. It gathers all the elements of demand that do not depend on actual income or its expected growth. In our private and closed economy, it includes autonomous consumption usually related to expensive luxury goods; modernization investment of firms aimed at transforming productive capacity instead of increasing it; and residential investment. We can separate the permanent elements ( $Z^{*}$ that grows at the autonomous trend, $g_{z}{ }^{*}$ ) and the transient demand $\left(Z^{\prime}\right)$. Credit conditions influence both of them.

Introducing (2), (3), and (4) into (1) we obtain the equilibrium level of output as the multiplier $(\mathrm{m})$ times autonomous demand or as the supermultiplier $(\mathrm{sm})$ times proper autonomous demand. In the second case, to ensure the stability of the system, it is necessary to distinguish between permanent and transient autonomous demand. The supermultiplier should be applied only to the first one (Dejuán 2016).

$$
\begin{aligned}
& Y_{t}=m \cdot\left(I_{t}+Z_{t}\right)=(\mathrm{sm}) \cdot Z_{t}^{*}+m \cdot Z^{\prime} \\
& m=\frac{1}{1-c\left(1-t^{\prime}\right)} ;(\mathrm{sm})=\frac{1}{1-c\left(1-t^{\prime}\right)-k^{*} \cdot g_{d}^{*}}
\end{aligned}
$$


Applying to the long run, the logic of the principle of effective demand, we can state that the rate of growth of real output will follow the expected growth of autonomous demand. The actual rate of growth of aggregate demand and real output takes into account both permanent and transient autonomous demand $\left(Z^{*}\right.$ and $Z^{\prime}$ in equation (6)). It is supposed to gravitate around the expected permanent growth of demand, provided these expectations last long enough (equation (7)).

$$
\begin{aligned}
\gamma_{t}=\frac{Y_{t}-Y_{t-1}}{Y_{t-1}} & =f_{1}\left(g\left[Z+Z^{\prime}\right]\right) \\
\gamma^{*} & =g_{z}^{*}
\end{aligned}
$$

The growth of output may occur with or without inflation. Post-Keynesian models usually rely on the cost-push inflation hypothesis embedded in the Phillips curve. An acceleration of growth is supposed to create tensions in the labor market, raising nominal wages and prices. In our globalized economy, where firms can hire any number of immigrants at the current wage, cost-push inflation is rather defused. The actual rate of output inflation $\left(\pi_{y, t}\right)$ tends to the 'official' inflation rate targeted by the Central Bank $\left(\pi_{o}\right)$. This can be considered as the long-run equilibrium of output inflation $\left(\pi_{y}{ }^{*}\right)$.

$$
\pi_{y}^{*}=\pi_{o}
$$

\section{THE FINANCIAL SECTOR: GROWTH OF CREDIT MONEY FOR OUTPUT AND NON-OUTPUT TRANSACTIONS}

The processes of production, distribution and demand, which we analysed earlier, would be impossible without a financial system that provides means of payments (money) and intermediates between agents in a deficit position (net borrowers) and agents in a surplus position (net lenders).

One of the pillars of post-Keynesian economics is the endogeneity of money. 'Money is credit driven and demand determined' (Moore 1988, p. 28). Graziani (2003) relates the demand for short-term credit money to the nominal wages advanced at the beginning of the production process. These loans are supposed to increase in parallel to the growth of nominal output.

The hypothesis of money endogeneity, although important and correct in itself, may convey a wrong idea: the passivity of banks. Minsky $(1964 ; 1982 ; 1986)$ made clear the active role of banks by searching for borrowers and changing creditworthiness criteria along the cycle.

Werner $(1997 ; 2012 ; 2015)$ brought to the fore the use of credit to finance non-output transactions, in particular the purchase of shares, land, and old houses. He provided a shortcut to measure the growth of credit for non-output transactions, namely the difference between the total growth of credit and the growth of nominal GDP.

On this basis, we can describe the financial system by the following equations:

$$
\begin{gathered}
C R_{t}=C R_{y, t}+\left[C R_{x, t}\right]=C R_{y, t}+\left[C R_{b, t}+C R_{a, t}\right] \\
\varphi_{t}=g(C R)=\varphi_{y, t}+\left[\varphi_{x, t}\right]=\varphi_{y, t}+\left[\varphi_{a, t}+\varphi_{b, t}\right] \\
\varphi_{t}=f_{2}\left(\delta_{t}^{\#}, \beta_{t}^{\#}, \pi_{a, t}^{\#}\right) \\
\varphi^{*}=\gamma^{*}+\pi_{y}^{*}+h^{*}=\gamma^{*}+\pi_{a}^{*}
\end{gathered}
$$




$$
\begin{gathered}
\pi_{a, t}=f\left(\varphi_{a, t}\right) \\
P_{a, i}^{*}=\frac{R_{i}}{r^{*}} .
\end{gathered}
$$

Equation (9) differentiates between credit for output transactions $\left(C R_{y}\right)$ and credit for non-output transactions $\left(C R_{x}\right)$. The last one can be split into two categories: (i) speculative credit that purchases assets with the expectation of capital gains $\left(C R_{a}\right)$; and (ii) risky or deepening credit that raises the proportion of productive and residential investment funded by loans $\left(C R_{b}\right)$. Both speculative and risky loans push up the indebtedness ratio.

Equation (10) defines $\varphi$ as the rate of growth of total credit, sum of the rates of loans for output $\left(\varphi_{y}\right)$ and loans for non-output transactions $\left(\varphi_{x}=\varphi_{a}+\varphi_{b}\right)$. Credit expansion depends on bank profitability free of risk. As indicated in equation (11) and Table 1, the financial risks augment (and credit decelerates) when there is a significant rise of the default rate $(\delta)$, the ratio of indebtedness $(\beta)$ and asset inflation $\left(\pi_{a}\right)$. What matters is the deviation of the variables from their normal positions, marked by an asterisk.

The 'normal' growth of credit $\left(\varphi^{*}\right)$ is defined by the rate that keeps indebtedness and asset inflation equal to or below their 'critical levels' $\left(\beta^{*}, \pi_{a}{ }^{*}\right)$. Equation (12) defines it by the sum of the normal growth of output (that we have identified with the autonomous trend, $\left.\gamma^{*}=g_{z}{ }^{*}\right)$ and the normal rate of inflation identified with the official inflation target $\left(\pi_{y}^{*}=\pi_{o}\right)$. We can add an additional term $\left(h^{*}\right)$. It allows the required liquidity in the stock exchange free from the risk of accelerating asset inflation. The normal asset inflation is: $\pi_{a}{ }^{*}=\pi_{y}{ }^{*}+h^{*}$. When the actual asset inflation is below this level we can assume a positive feedback effect of potential capital gains on speculative credit linked to self-fulfilling prophecies. Also a positive effect on credit for output transactions linked to wealth effects. When asset inflation surpasses this threshold, and speculators start the retreat, we can expect a negative impact on loans for output and non-output transactions.

Equation (13) states that actual asset inflation depends on the rate of growth of speculative credit $\left(\varphi_{a}\right)$. Werner (1997) explains this hypothesis by means of the 'quatitative theory of credit.' Since the supply of assets is fixed (or moves smoothly), a sharp increase of the demand for them (funded by loans) is bound to raise their prices. The bubble will be afloat as long as the flow of speculative credit goes on.

\section{Table 1 Factors negatively affecting creditworthiness and credit expansion}

\begin{tabular}{lccl}
\hline Variables & $\begin{array}{c}\text { Definition of } \\
\text { variables }\end{array}$ & Critical levels & Results \\
\hline Credit default rate & $\delta=\frac{\text { credits defaulted }}{\text { outstanding debt }}$ & $\delta>\delta^{*}, \delta^{\#}>0$ & Confidence effect (deterioration) \\
Indebtedness ratio & $\beta=\frac{\text { outstanding debt }}{\text { income }}$ & $\beta>\beta^{*}, \beta^{\#}>0$ & $\begin{array}{c}\text { Deflationary effect of the burden of } \\
\text { debt }\end{array}$ \\
$\begin{array}{l}\text { Asset inflation } \\
\text { (bubbles) }\end{array}$ & $\pi_{a t}=\frac{P_{a t}-P_{a(t-1)}}{P_{a(t-1)}}$ & $\pi_{a}>\pi_{a}^{*}+h^{*}$ & $\begin{array}{c}\text { Vertigo effects and fall of asset } \\
\text { prices } \\
\text { Wealth effects (eventually } \\
\text { negative) }\end{array}$ \\
\end{tabular}

Note: Some of these ratios involve flows and stocks. The sign (\#) indicates deviations of the variables from their normal variables $(*)$. Example: $\delta_{t}^{\#}=\left(\delta_{t}-\delta^{*}\right) / \delta^{*}$. 
Implicit in this account is the hypothesis of a normal or fundamental price for assets. This is compatible with the Sraffian theory of prices of production embedded in our post-Keynesian system (Sraffa 1960). According to (14), the demand price of the share of a competitive firm $i$ is the discounted flow of expected profits. Its supply price is associated with the cost of reproducing the capital for the firm. If we take as a discount rate the normal rate of profit ( $r^{*}$, in the Sraffian sense), both prices coincide and Tobin's $q$ will be equal to one. The market price of the shares of this firm may deviate from the normal value given in (14). Yet it continues playing as a gravity center.

\section{INTERACTIONS BETWEEN THE TWO SECTORS IN DIFFERENT PREDATOR-PREY MODELS}

A predator-prey model is represented by a simultaneous system of differential equations. Equation (15) and Figure 5 schematize it.

$$
\begin{aligned}
\varphi^{\prime} & =a_{1}(\gamma, \varphi) \\
\gamma^{\prime} & =a_{2}(\gamma, \varphi)
\end{aligned}
$$

$\gamma$ is the rate of growth of real GDP, the prey of our model. $\varphi$ is the rate of growth of credit. It becomes a predator, when it raises the indebtedness ratio above $\beta^{*}$. This is equivalent to saying that credit for non-output transactions expands faster than credit for output transactions. $\gamma^{\prime}$ and $\varphi^{\prime}$ refer to the first derivative of our variables with respect to time; they capture their current movement. What matters for the dynamics of the system are the deviations from their long-term equilibrium rates: $\gamma^{\#}=\left(\gamma_{t}-\gamma^{*}\right) / \gamma^{*}$ and $\varphi^{\#}=\left(\varphi_{t}-\varphi^{*}\right) / \varphi^{*}$. As a reminder: $\gamma^{*}$ is the expected growth of permanent demand and $\varphi^{*}$ adds to the previous rate the normal rate of output inflation (linked to the official inflation target). Parameters $a_{12}$ and $a_{21}$ measure the sensitivity of $\gamma$ and $\varphi$ to the deviations of the other variable; $a_{22}$ is the auto-acceleration of speculative credit; $a_{11}$ is the auto-acceleration of economic growth. In the two models analysed below, we make $a_{11}=0$ in order to focus on the instability forces accruing from the financial side. In other words, the expected growth of permanent demand (to which output adjusts) is assumed to be constant during the period of our analysis. The actual rate may change due to the movements of transient demand funded by loans. Even if firms operate at normal capacity, they can meet moderate increases in transient demand by raising capacity utilization.

In this section our interest is in ascertaining the stability of the two models and the type of financial regulation that could make them more stable. In Appendix 1, following the trace-determinant analysis, we verify the stability conditions and provide an algebraic approach to the qualitative behavior of these models.

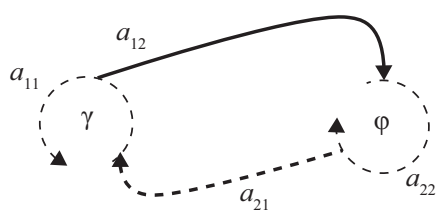

Figure 5 General view of the predator-prey model 


\subsection{Model 1: risky finance without speculation - the negative impact of overindebtedness}

We have designed our basic model to be formally equivalent to the original LotkaVolterra prey-predator model. The differences: we deal with rates of growth instead of levels and we focus on deviations from their normal rates, instead of absolute increments.

The reduced form of model 1 is: $:^{5}$

$$
\begin{gathered}
\frac{\varphi^{\prime}}{(\varphi+\bar{\varphi})}=a_{12} \cdot \gamma^{\#} \\
\frac{\gamma^{\prime}}{(\gamma+\bar{\gamma})}=-a_{21} \cdot \varphi^{\#} .
\end{gathered}
$$

$a_{12}$ accounts for the parallel evolution of $\gamma$ and $\varphi$. According to Minsky (1986), the fall in the default rate after a period of tranquility invites banks to relax the creditworthiness criteria: the confidence effect (see equation (11)).

The discontinuous arrow labeled ' $-a_{21}$ ' shows that credit acceleration has (eventually) a negative impact on the performance of the real economy. Firms and households will take advantage of the credit facilities. The rate of growth of autonomous demand, aggregate demand, and output will accelerate according to equation (6). Even if firms were operating at normal capacity there is always the possibility to increase it in the short run to meet transient demand and to accelerate investment to meet the increasing permanent demand. As we saw in Section 3, an increase in the potential rate of growth is possible if credit raises the share of productive investment in income. Obviously, there are technological limits to the overuse of capacity and the acceleration of the potential rate. If credit expansion surpasses these limits, the result would be an increase in the indebtedness ratio. The new loans will be adding more to debt than to income. The same happens when firms and households are willing to raise the percentage of their investments funded with credit (Sau 2015).

This burden of debt is embodied in the term $t^{\prime}=i^{\prime} \cdot \beta$ that appears in the consumption and multiplier functions (equations (2) and (5)). It operates from the first dollar lent which triggers a flow from borrowers to banks, without any guarantee that they will lend it again. ${ }^{6}$ For a time, the positive impact of credit on demand supersedes the negative impact of debt. Yet when the indebtedness ratio surpasses a critical threshold $\left(\beta_{t}>\beta^{*}\right)$, the second effect will prevail. This deflationary effect is especially harmful in recessions when the repayment flows go on, while credit and income fall.

In Figure 6, a time diagram, we observe the evolution of the two series $(\gamma$ and $\varphi)$, given the initial positions set in Appendix 1. They describe regular cycles, more pronounced in the financial sector, as is usually the case. Figure 7 shows its complementary phase diagram. The demarcation curves (isoclines) are vertical and horizontal lines starting at the normal or critical values of output growth $\left(\gamma^{*}\right)$ and credit growth $\left(\varphi^{*}\right)$.

5. The fixed parameters $\bar{\varphi}, \bar{\gamma}$ serve to fix the position of the graph.

6. In this paper we abstract from interest-rate movements under the assumption that they are controlled by the Central Bank. As a matter of fact, market interest rates include an element of risk that is linked to the default rate. If we assume that market rates rise at the end of booms and the beginning of recessions, the previous results derived from the inspection of the indebtedness ratio would be reinforced. 


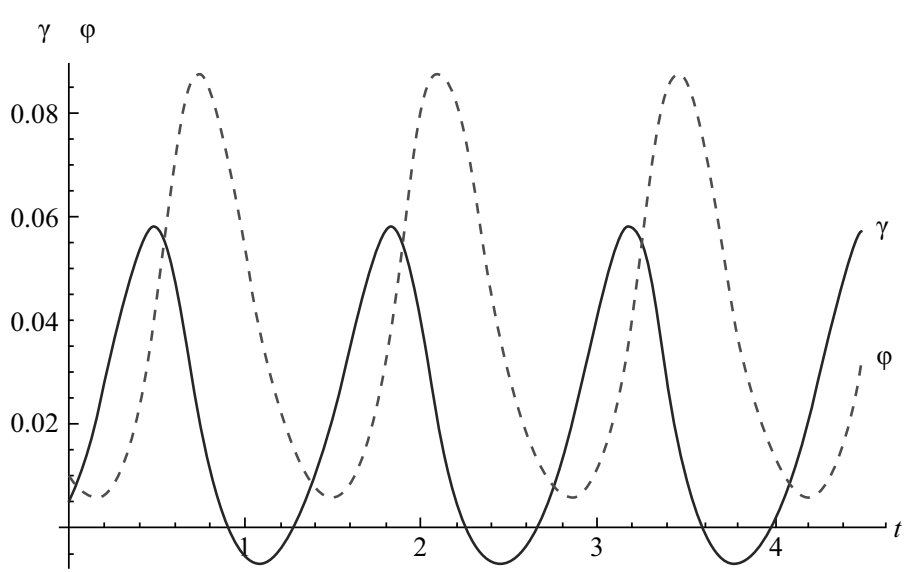

Figure 6 Time diagram: regular cycles

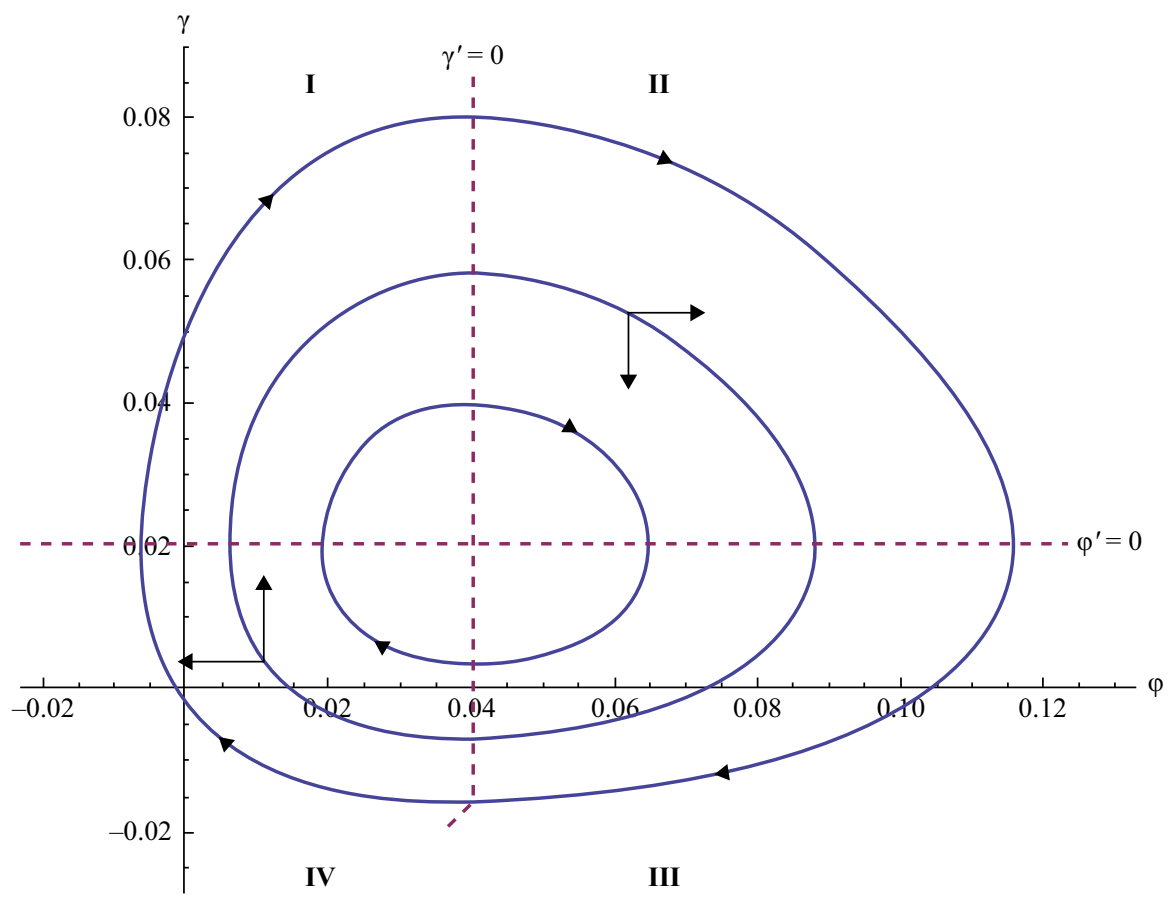

Figure 7 Phase diagram: closed orbits

They divide the economy into four regions. The arrows indicate the direction of the movements, clockwise in our case. ${ }^{7}$

7. Clockwise cycles are the normal outcome in the financial-real interplay (Ryoo, 2013a; 2013b). Goodwin (1967), in his first predator-prey model that ignored financial variables, obtained counter-clockwise movements. 
In region I, output grows above the normal rate but credit grows even faster. In region II, once $\beta_{t}>\beta^{*}$, the growth of output decelerates. In region III it falls below the normal rate and the increasing ratio of defaults sends banks a signal to decelerate credit. In region IV, when the indebtedness ratio falls below $\beta^{*}$, output resumes its recovery at an increasing rhythm. The cycle resumes.

As in the Lotka-Volterra model, the solution set is a family of orbits whose size depends on the initial conditions. There is a risk of stampede when $\varphi$ and $\gamma$ deviate too much from their normal values (as happens in the external, broadest orbit). Banks may end up mistrusting their customers and even their own partners. The ongoing illiquidity may trigger a credit crunch that would cause the financial and the economic systems to collapse altogether. In severe recessions, the propensities to consume and invest may fall and reduce the multiplier effects of a shrinking autonomous demand that gets no funding. 'A balance sheet recession,' in the words of Koo (2011), is deployed.

Note that the stampede effects and the balance-sheet recessions are not part of the normal financial cycle but are quite possible. This danger vindicates the use of macroeconomic policy to offset external shocks leading to extreme situations. Macroprudential regulation also seems convenient to check the relaxation of the creditworthiness criteria. The capital requirements proposed by the Basel agreements accomplish this function.

In our model, the check can be introduced by adding to the first equation in (16a) a negative quadratic term. This gives us the following expression:

$$
\frac{\varphi^{\prime}}{(\varphi+\bar{\varphi})}=a_{12} \cdot \gamma^{\#}-a_{0(1)} \cdot \varphi^{2} .
$$

The check has important effects on the dynamics of the model. The new system exhibits structural stability in the form of a spiral node for a broad array of feasible values for $a_{(0) 1}$. The economy tends to stabilize in the steady state $\left(\gamma^{*}, \varphi^{*}\right)$, as we observe in Figure 8. Certainly, full convergence may require too much time and will be disrupted by a variety of shocks. In spite of such evidence, we can conclude that checks to risky credit enhance the stability of the system. The narrowing of the actual orbit in Figure 7 should be considered a success.

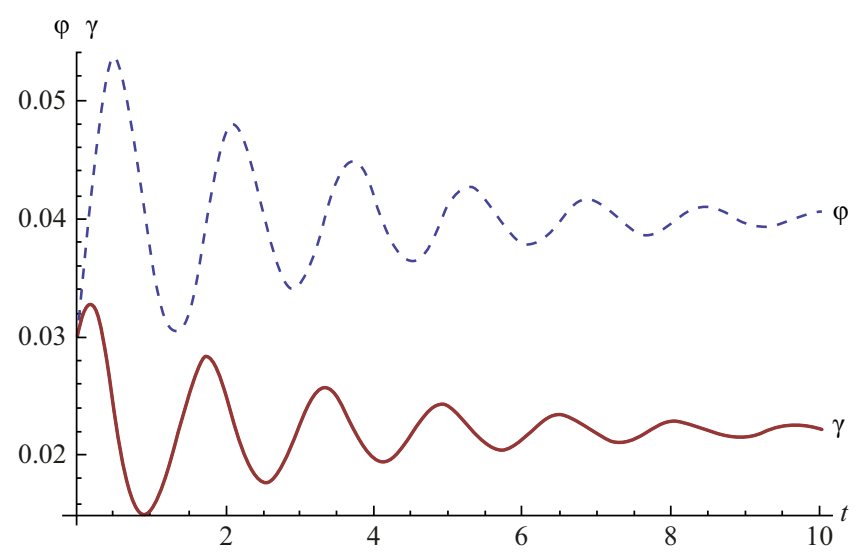

Figure 8 Asymptotic stability after the introduction of checks to credit supply 


\subsection{Model 2: Risky and speculative finance - the impact of overindebtedness- cum-bubbles}

The relaxation of the creditworthiness criteria will be exploited by speculators eager to buy assets under the expectation of reselling them soon with capital gains. We are in the realm of self-fulfilling prophecies: the capital gains encourage speculators to continue borrowing to buy assets at an even higher price. The auto-acceleration of asset inflation is reflected in the positive sign of $a_{22}$. Yet when the gap between the market price of assets and their fundamental value surpasses a given threshold $\left(h^{*}\right)$, speculators can suffer from vertigo and start to sell assets. The negative sign preceding the parameter $a_{0(2)}$ shows this effect. Hopefully the bubble will deflate slowly without triggering a credit crunch.

The dynamics of speculative credit impacts on the real economy. By increasing the value of the assets used as collateral, firms and households obtain loans more easily. In the first phase, aggregate demand and output benefit from positive wealth effects. In the second phase, when asset prices fall, wealth effects turn out negative. Speculative loans are the main force behind over-indebtedness. They increase debt without altering income, since capital gains are a zero sum game. The deflationary effect of debt will be felt via the coefficient $(-) a_{12}$.

The reduced form of the system of equations in model 2 looks like this:

$$
\begin{gathered}
\frac{\varphi^{\prime}}{(\varphi+\bar{\varphi})}=a_{12} \cdot \gamma^{\#}+a_{22} \cdot \varphi^{\#}-a_{0(2)} \cdot \varphi^{2} \\
\frac{\gamma^{\prime}}{(\gamma+\bar{\gamma})}=-a_{21}^{\prime} \cdot \varphi^{\#} .
\end{gathered}
$$

The phase diagram corresponding to the new system depicts a limit cycle like the one shown in Figure 9. This is a rare outcome of dynamic models, but as we explain in Appendix 1, it is possible and plausible in our case. As usual, the intersection of the demarcation curves corresponding to the normal pair of values $\left(\gamma^{*}\right.$ and $\left.\varphi^{*}\right)$ defines a long-run equilibrium position. Now, if an exogenous shock moves the variables above or below their normal values, the economy will converge towards one specific orbit, the one represented by the darkest part of Figure 9.

Again, there is a risk of stampede when the economy reaches extreme positions. After the bursting of the bubble, the real economy may enter into recession because of a credit crunch and a general fall in the prices of assets. To avoid such a fatal outcome, regulators should reinforce the check implicit in the parameter $a_{0(2)}$ by taxing the capital gains or by restricting the funding of speculative investments with new credit. In Figure 9 the check has been chosen so that the limit cycle (dark orbit) falls in the positive quadrant. ${ }^{8}$

What would happen if $a_{0(2)}=0$ ? This means that there is no market check of the auto-acceleration movements in the speculative circuit and that the regulators are not concerned with it. As reflected in Figure 10, the system would collapse sooner rather than later. The new model is inherently unstable. No matter how sensitive the

8. In the previous model there was a broad range of feasible values able to transform the orbit into asymptotic stability. In the presence of speculation, the values able to produce this result are few and, probably, unfeasible. We'd better search for the parameter that narrows the limit cycle and locate it in the positive quadrant (see the dark orbit of Figure 9). 
172 Review of Keynesian Economics, Vol. 6 No. 2

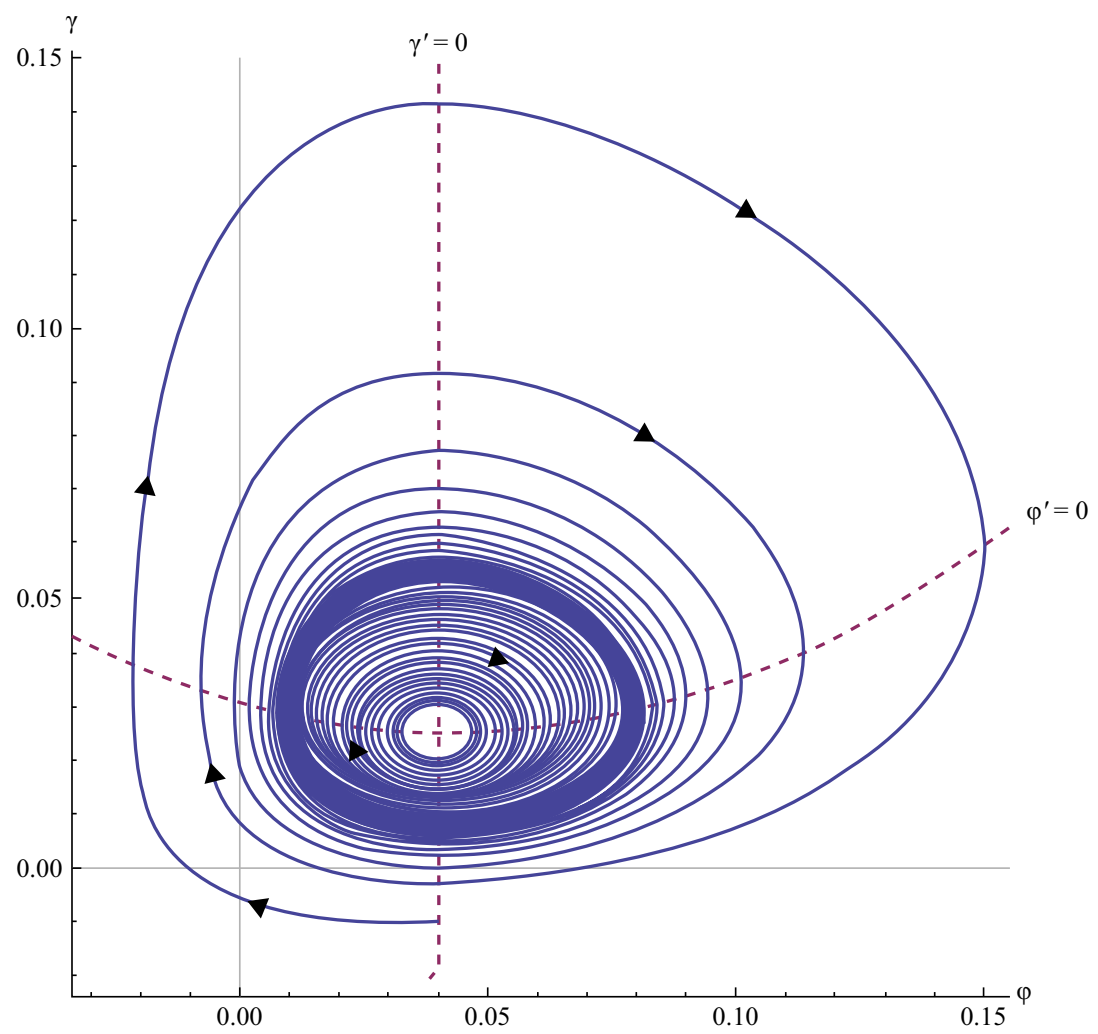

Figure 9 Limit cycle when speculation is bounded

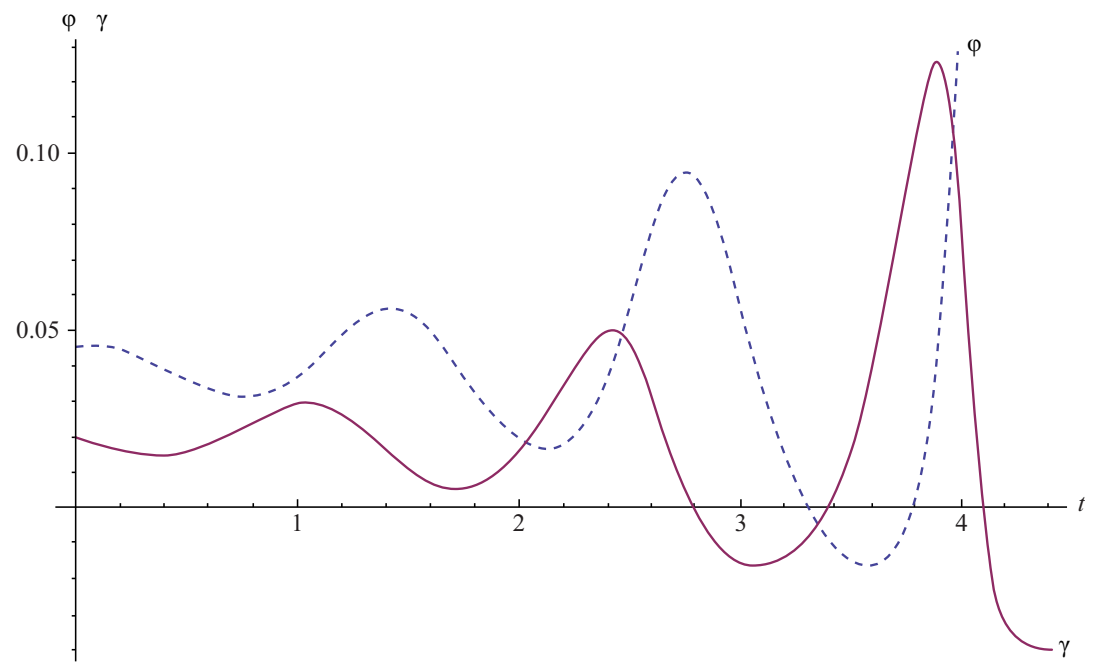

Figure 10 Explosive cycles when speculation is unbounded 
economic agents are to the deviations, the system is bound to explode. This result reinforces the need for financial regulation. ${ }^{9}$

\section{CONCLUSIONS}

1. The interaction between the productive and the financial sectors observed in the dynamics of capitalist economies can be properly captured by a predator-prey model that distinguishes between actual and normal positions of key variables. In this paper we focus on the cycles ignited in the part of the financial sector that grants loans for non-output transaction, usually with a risky and speculative flavor.

2. In the productive sector (circuit for output transactions), firms produce the final output and incomes are distributed and allocated with the help of traditional finance. This is a positive game: the increasing output makes possible a parallel increase in the wealth of all the participants. The prey of our model has been identified with the rate of growth of real GDP $(\gamma)$. It 'tends' to grow efficiently at the expected rate of growth of permanent autonomous demand. 'Efficiently' means a tendency towards normal capacity, not full employment.

3. The circuit for non-output transactions constitutes a zero sum game. The predator is associated with the growth of credit money for non-output transactions. Following Werner (1997) we proxy this with the growth of total credit above the growth of nominal GDP $(\varphi)$. It can be split into the speculative credit in search for capital gains and the risky credit that increases the part of business and household investment financed with credit. In both cases, the indebtedness ratio is bound to rise and cause a deflationary impact on aggregate demand.

4. Minsky (1986) provides the best explanation for the positive link between $\gamma$ and $\varphi$, here represented by $(+) a_{12}$. The fall of the default rate during tranquil periods when firms operate at normal capacity makes banks relax their creditworthiness criteria, both for output and non-output transactions.

5. If credit is growing above nominal GDP, the rise of the indebtedness ratio above a critical value will raise the burden of debt, reduce the multiplier, and cause a deflationary impact on the aggregate demand via $(-) a_{21}$. When banks become aware of the increasing risk and observe an acceleration of defaults, they will curtail loans to finance autonomous demand, the engine of the system. Add the negative impact of wealth effects when asset prices plummet and we have a full explanation for the (eventual) negative sign of coefficient $a_{21}$.

6. Prey-predator models generate cycles that can be self-contained or explosive. The second case is the result of unbounded speculation that leads to a collapse of the economy sooner rather than later. In the absence of speculation we obtain closed orbits whose sizes depend on the initial conditions. If speculation exists but is bounded, we can expect a limit cycle. Note that even self-contained cycles can lead to an abrupt collapse when the prices of assets and the leverage of firms reach extreme positions, prompting a stampede in the stock exchange and a credit crunch in the banking system.

7. In credit-led economies, the risk of creating asset bubbles and explosive cycles increases dramatically. The so-called 'originate to distribute model of banking'

9. Recent books by people with important responsibilities in financial institutions and financial regulation support similar conclusions. See Turner (2015) and King (2016). 
174 Review of Keynesian Economics, Vol. 6 No. 2

has speeded up the transition from sound, to risky, and to speculative finance. The connivance of traditional banks (able to create money simply by granting credit) and the shadow banking system (that conceals risk via securitization and derivative products) has proved to be deleterious.

8. Macroeconomic policies and financial regulation should introduce checks to reduce the size of closed orbits and limit cycles. Higher taxes on capital gains and higher capital requirements should be reinforced with discriminatory rules on credit allocation. The privilege of banks to create money should be restricted to the finance of output transactions. Banks should not be allowed to finance investments on assets that usually have a speculative purpose and inflate bubbles. Some decades ago, the discriminatory regulation we propose would have been unfeasible. Nowadays, central banks have the information and the instruments required to enforce it.

\section{ACKNOWLEDGMENTS}

Richard Werner (Southampton Management School) made useful comments on a first draft of this paper. Our research received financial support from the European Fund for Regional Development and Junta de Comunidades de Castilla-La Mancha (Project PPII-2014-006-P). We acknowledge the useful comments of two reviewers. All errors remain ours.

\section{REFERENCES}

Arnim, Rudiger von and José Barrales (2015), 'Demand-driven Goodwin cycles with Kaldorial and Kaleckian features,' Review of Keynesian Economics, 3, 351-373.

Asada, Toichiro (2001), 'Nonlinear dynamics of debt and capital: a Post-Keynesian analysis,' in Yuji Aruka (ed.), Evolutionary Controversies in Economics: A New Transdisciplinary Approach, Tokyo: Springer, pp. 73-87.

Asada, Toichiro (2011), 'Modeling financial instability,' Chuo University Working Papers 2011-1.

Asada, T., C. Charella, P. Flaschel, and R. Franke (2010), Monetary Macrodynamics, Abingdon, UK: Routledge.

Badhuri, A., K. Laski, and M. Riese (2006), 'A model of interaction between the virtual and the real economy,' Metroeconomica, 57, 417-427.

Bortis, Heinrich (1997), Institutions, Behaviour and Economic Theory: A Contribution to Classical-Keynesian Political Economy, Cambridge, UK: Cambridge University Press.

Dafermos, Yannis (2014), 'Debt cycles, instability and fiscal rules: a Godley-Minsky model,' Working Paper, University of the West of England, Bristol, available at: http://eprints. uwe.ac.uk/26694.

Dejuán, Óscar (2005), 'Paths of accumulation and growth: towards a Keynesian long-period theory of output,' Review of Political Economy, 17(2), 231-252.

Dejuán, Óscar (2016), 'Hidden links in the warranted rate of growth: the supermuliplier way out,' European Journal of the History of Economic Thought, 24(4), 369-394.

Dejuán, Óscar and Josep González-Calvet (2005), 'Inestabilidd financiera y ciclos a partir de un modelo depredador-presa,' Investigación Económica, LXIV(251), 53-84.

Eatwell, John (1983), 'The long-period theory of unemployment,' Cambridge Journal of Economics, 7(3), 269-285.

Eatwell, John (2012), 'The theory of value and the foundations of economic policy: in memoriam of Piarangelo Garegnani,' Contributions to Political Economy, 31, 1-18. 
Fazzari, S., P. Ferri, and E. Greenberg (2008), 'Cash flow, investment and Keynes-Minsky cycles,' Journal of Economic Behaviour and Organization, 65, 555-572.

Gandolfo, Giancarlo (2009), Economic Dynamics, Berlin: Springer.

Godley, Wynne and Marc Lavoie (2006), Monetary Economics: An Integrated Approach to Credit, Money, Income, Production and Wealth, New York: Palgrave.

González-Calvet, Josep (1999), 'Los ciclos: aspectos reales y financieros,' in Josep M. Bricall and Óscar Dejuán (eds), Economía política del crecimiento, fluctuaciones y crisis, Barcelona: Ariel, pp. 137-173.

Goodwin, Richard M. (1967), 'A growth cycle,' in C.H. Feinstein (ed.), Socialism, Capitalism and Economic Growth, Cambridge, UK: Cambridge University Press, pp. 54-63.

Goodwin, R.M., M. Drüger, and A. Vercelli (1984), Nonlinear Models of Fluctuating Growth, Berlin: Springer-Verlag.

Graziani, Augusto (2003), The Monetary Theory of Production, Cambridge, UK: Cambridge University Press.

Hein, Eckhard (2012), The Macroeconomics of Finance-Dominated Capitalism - and its Critics, Cheltenham, UK and Northampton, MA: Edward Elgar.

Hicks, John (1950), A Contribution to the Theory of the Trade Cycle, Oxford: The Clarendon Press.

Kalecki, Michael (1971), Selected Essays in the Dynamics of the Capitalist Economy (19331970), Cambridge, UK: Cambridge University Press.

Keynes, John M. (1936), The General Theory of Employment, Interest and Money, London: Macmillan.

Kindleberger, Charles P. (1978 [1996]), Manias, Panics and Crashes: A History of Financial Crises, Basingstoke, UK: Macmillan.

King, Mervyn (2016), The End of Alchemy: Money, Banking and the Future of the Global Economy, New York: Norton.

Koo, Richard C. (2011), 'The world in balance sheet recession: causes, cures and politics,' Real-World Economics Review, 58(12), 19-37. (Reprinted in O. Dejuán, E. Febrero, and J. Uxó (2013), Post-Keynesian Views of the Crisis and its Remedies, pp. 46-66.)

Minsky, Hyman P. (1964), 'Longer waves in financial relations: financial factors in the severe depressions,' The American Economic Review, 54(3), 83-96.

Minsky, Hyman P. (1982), Can 'it' Happen Again?, Armonk, NY: M.E. Sharpe.

Minsky, Hyman P.(1986), Stabilizing an Unstable Economy, New Haven, CT: Yale University Press.

Minsky, Hyman P. (1992), 'The financial instability hypothesis,' Working Paper, no 74, The Jerome Levy Economics Institute of Bard College, New York. (Reprinted in P. Arestis and M. Sawyer (eds) (1994), Handbook of Radical Political Economy, Aldershot, UK and Brookfield, VT: Edward Elgar, pp. 148-157.)

Moore, Basil J. (1988), Horizontalists and Verticalists: The Macroeconomics of Credit-Money, Cambridge, UK: Cambridge University Press.

Oreiro, J.L., S.R. Stancato de Souza, C. Vila Nova de Souza, and K. Pereira Guedes (2013), 'Regla de Taylor y burbujas especulativas en un modelo Keynes-Minsky de fluctuaciones cíclicas,' Investigación Económica, LXXII(283), 31-67.

Palley, Thomas I. (1994), 'Debt, aggregate demand, and the business cycle: an analysis in the spirit of Kaldor and Minsky,' Journal of Post Keynesian Economics, 16, 371-390.

Palley, Thomas I. (2011), 'A theory of Minsky super-cycles and financial crises,' Contributions to Political Economy, 30, 31-46.

Palley, Thomas I. (2013), Financialization: The Economics of Finance Domination, New York: Palgrave-Macmillan.

Ryoo, Soon (2013a), 'Bank profitability, leverage and financial instability: a Minsky-Harrod model,' Cambridge Journal of Economics, 37(5), 1127-1160.

Ryoo, Soon (2013b), 'Minsky cycles in Keynesian models of growth and distribution,' Review of Keynesian Economics, 1(1), 37-70.

Ryoo, Soon and Peter Skott (2008), 'Financialization in Kaleckian economics with and without labour constraints,' Intervention. European Journal of Economics and Economic Policies, $5,357-386$. 
176 Review of Keynesian Economics, Vol. 6 No. 2

Sau, Lino (2015), 'Debt deflation worries: a restatement,' Review of Keynesian Economics, 3, 279-294.

Semmler, Willi (1995), Financial Dynamics and Business Cycles, New York: Sharpe.

Serrano, Franklin (1995), 'Long period effective demand and the Sraffian supermultiplier,' Contributions to Political Economy, 14, 67-90.

Serrano, Franklin and Fabio Freitas (2015), 'Growth rate and level effects: the adjustment of capacity to demand and the Sraffian supermultiplier,' Review of Political Economy, 27(3), 258-281.

Skott, Peter (1994), 'On the modelling of systemic financial fragility,' in A.K. Dutt (ed.), New Directions in Analytical Political Economy, Cheltenham, UK and Northampton, MA: Edward Elgar, pp. 49-76.

Skott, Peter and Soon Ryoo (2008), 'Macroeconomic implications of financialization,' Cambridge Journal of Economics, 28, 719-741.

Sraffa, Piero (1960), Production of Commodities by Means of Commodities, Cambridge, UK: Cambridge University Press.

Taylor, Lance (2012), 'Growth cycles, asset price and finance,' Metroeconomica, 63(1), 40-63.

Taylor, Lance, and Stephen A. O'Connell (1985), 'A Minsky crisis,' The Quarterly Journal of Economics, 100(Supplement), 871-885.

Turner, Adair (2015), Between Debt and the Devil: Money, Credit and Fixing Global Finance, Princeton, NJ: Princeton University Press.

Volterra, Vito (1926), 'Variazioni efluttuacioni del numero d'individui in specie animali conviventi,' Mem. Academia dei Licei Roma, 2, 31-113.

Werner, Richard A. (1997), 'Towards a new monetary paradigm: a quantity theorem of disaggregated credit, with evidence from Japan,' Kredit und Kapital, 30(2), 276-309.

Werner, Richard A. (2005), New Paradigm in Macroeconomics, Basingstoke, UK: Palgrave Macmillan.

Werner, Richard A. (2012), 'Towards a new research programme on "banking and the economy": implications of the Quantity Theory of Credit for the prevention and resolution of banking and debt crises,' International Review of Financial Analysis, 25, 1-17.

Werner, Richard A. (2015), 'The quantity theory of credit,' in L.-P. Rochon and S. Rossi (eds), The Encyclopedia of Central Banking, Cheltenham, UK and Northampton, MA: Edward Elgar, pp. 416-418. 


\section{APPENDIX 1}

In order to show the evolution of our predator $(\varphi)$ and prey $(\gamma)$ we formulate a nonlinear system of autonomous first-order ordinary differential equations. The trace and determinant of the implicit Jacobian matrix informs about the local stability of the dynamic system.

Table A1 summarizes the values of the parameters of the two models we are going to explore (each one with two variants). They have been chosen among those values that are economically meaningful and whose effects can be easily visualized. Of course, there are many other reasonable combinations of parameters. (González-Calvet 1999 and Gandolfo 2009 explored the economic significance of the parameters.)

\section{A1.1 Model 1}

Our first model is formally equivalent to the original Lotka-Volterra predator-prey model. It corresponds to equation (16a) in the main text:

$$
\begin{gathered}
\frac{\varphi^{\prime}}{\varphi+\bar{\varphi}}=a_{12} \cdot \gamma^{\#} \\
\frac{\gamma^{\prime}}{\gamma+\bar{\gamma}}=-a_{21}^{\prime} \cdot \varphi^{\#} .
\end{gathered}
$$

The Jacobian of the autonomous non-linear dynamic system, evaluated at the stationary point $\varphi_{e q}=\varphi^{*}$ and $\gamma_{e q}=\gamma^{*}$, takes the following values:

$$
J=\left[\begin{array}{cc}
\varphi^{\prime}{ }_{\varphi}=0 & \varphi^{\prime}{ }_{\gamma}=\frac{\mathrm{a}_{12}\left(\bar{\varphi}+\varphi^{*}\right)}{\gamma^{*}} \\
\gamma_{\varphi}^{\prime}=-\frac{\mathrm{a}_{21}\left(\bar{\gamma}+\gamma^{*}\right)}{\varphi^{*}} & \gamma_{\gamma}^{\prime}=0
\end{array}\right]=\left[\begin{array}{cc}
0 & + \\
- & 0
\end{array}\right] .
$$

Table A1 Parameters of the models

\begin{tabular}{lllll}
\hline & $a_{12}$ & $a_{21}$ & $a_{22}$ & $a_{0}$ \\
\hline Model 1 (Figures 6 and 7) & 1.5 & 2.5 & 0 & 0 \\
Model 1' (Figure 8) & 1.5 & 2.5 & 0 & $10 a_{0(1)}$ \\
Model 2 (Figure 9) & 1.5 & 2.5 & 0.8 & $230 a_{0(2)}$ \\
Model 2' (Figure 10) & 1.5 & 2.5 & 0.8 & 0 \\
\hline
\end{tabular}

Notes:

1. Meaning of the parameters: $a_{12}=$ default and creditworthiness; $a_{21}=$ over-indebtedness and creditworthiness; $a_{22}=$ auto-acceleration effect of speculative credit; $a_{0(1)}=$ check on credit supply for output transactions that raise the indebtedness ratio; $a_{0(2)}=$ check on credit supply for speculation. In this appendix, the parameters are always positive. A negative impact is marked in the main text by a 'minus' sign.

2. Normal or long-term equilibrium values of the variables: $\gamma^{*}=0.02 ; \varphi^{*}=0.04$.

3. Initial positions: $\gamma_{o}=\gamma^{*}=0.03 ; \varphi_{o}$ is typically set a little above $\varphi^{*}$ in order to show the response of the model.

4. $\bar{\varphi}=0.04$ and $\bar{\gamma}=0.02$. This means that $\varphi$ cannot fall below -0.04 and $\gamma$ below -0.02 . They are used to fix the position of the cycles in our figures. 
Since the determinant is positive and the trace is zero, the eigenvalues of the Jacobian matrix evaluated at the stationary points will be purely imaginary. Hence, our long-term equilibrium $\left(\gamma^{*}, \varphi^{*}\right)$ is a center.

Figure 6 (in the main text) represents the time diagram. Figure 7 represents the phase diagram, where the isoclines are depicted with dashes. Note that values $(\gamma, \varphi)=(\bar{\gamma}, \bar{\varphi})$ represent a second set of isoclines for the trivial equilibrium (involving a saddle path).

We can introduce a check on the credit supply by adding the term $\left(-a_{o(1)} \cdot \varphi^{2}\right)$, shifting from (16a) to (16b). This will make the trace of the Jacobian negative. Consequently, our equilibrium will be a spiral node exhibiting asymptotic stability (as shown in Figure 8).

\section{A1.2 Model 2}

Our second model responds to equation (17).

$$
\begin{gathered}
\frac{\varphi^{\prime}}{(\varphi+\bar{\varphi})}=a_{12} \cdot \gamma^{\#}+a_{22} \cdot \varphi^{\#}-a_{0(2)} \cdot \varphi^{2} \\
\frac{\gamma^{\prime}}{(\gamma+\bar{\gamma})}=-a_{21}^{\prime} \cdot \varphi^{\#}
\end{gathered}
$$

The non-trivial steady state corresponds to: $\varphi_{e q}=\varphi^{*}$ and $\gamma_{e q}=\gamma^{*}\left(1+\frac{a_{0(2)}}{a_{12}} \varphi^{* 2}\right)$. Note that when $\varphi^{*^{2}}$ is close to zero, $\gamma_{e q} \approx \gamma^{*}$ as in model 1 .

The Jacobian matrix of the new dynamic system evaluated at the stationary point takes this form:

$$
J=\left[\begin{array}{cl}
\varphi_{\varphi}^{\prime}=\frac{\left(\bar{\varphi}+\varphi^{*}\right)\left(a_{22}-2 a_{0(2)} \varphi^{* 2}\right)}{\varphi^{*}} & \varphi_{\gamma}^{\prime}=\frac{a_{12}\left(\bar{\varphi}+\varphi^{*}\right)}{\gamma^{*}} \\
\gamma_{\varphi}^{\prime}=-\frac{a_{21}\left(\bar{\gamma}+\gamma^{*}+\frac{a_{0} \varphi^{* 2} \gamma^{*}}{a_{12}}\right)}{\varphi^{*}} & \gamma_{\gamma}^{\prime}=0
\end{array}\right]=\left[\begin{array}{cc}
? & + \\
- & 0
\end{array}\right] .
$$

The trace-determinant analysis around the stationary point leads to inconclusive results on stability. The qualitative behavior of the system near the stationary point will depend on the value of $\varphi_{\varphi}^{\prime}$.

The Poincaré-Bendixon theorem holds (and a limit cycle is warranted) for a broad range of economically meaningful values of the check. In our case (given the values of $a_{12}$ and $a_{21}$ in Table 1), we may get a limit cycle for $0<a_{0(2)}<250$ Two conditions are required to get the limit cycle: (i) $a_{22}-2 a_{0(2)} \varphi^{* 2}>0$, in order to ensure an unstable equilibrium; (ii) $\mathrm{a}_{22}^{2}{ }^{\prime}-4 a_{12} a_{22}{ }^{\prime} a_{22}{ }^{\prime \prime} \varphi^{*}-4 \mathrm{a}_{12}^{2} a_{22}{ }^{\prime \prime} \varphi^{* 2}<0$, in order to guarantee that this is the only equilibrium in the positive $\varphi-\gamma$ space (apart from the trivial equilibrium which corresponds to an unstable saddle path). Notice that when $a_{22}-2 a_{0(2)} \varphi^{* 2}<0$, that is, when $a_{0(2)}$ takes sufficiently high values (probably unfeasible), we go back to the case of asymptotic stability (spiral node) (model 1' and Figure 8 ). The high values required in $a_{(0) 2}$ are probably unfeasible, but the values that give a 'save' limit cycle, as in Figure 9, are quite normal. 
If we make $a_{0(2)}=0$, the checks on speculation disappear. The new model $\left(2^{\prime}\right)$ becomes unstable per se as we observe in the time diagram of Figure 10. The eigenvalues associated with $J^{\prime}(2)$ have a positive real component as both the trace and determinant are positive. The phase diagram exhibits explosive trajectories leading to an asymptotic infinite value of $\varphi$ and a zero value of $\gamma$. In contrast to model 2 , the Poincaré-Bendixon theorem does not hold in $2^{\prime}$. Thus we cannot construct a compact and invariant set around the (unstable) steady state. 